\title{
The importance of understanding perceptions of accessibility when addressing transport equity: A case study in Greater Nottingham, UK
}

\author{
Angela Curl \\ University of Canterbury \\ angela.curl@canterbury.ac.nz
}

\begin{abstract}
To deal with issues of equity in transport, increasing attention is being paid to addressing inequalities in accessibility. Existing approaches to measuring accessibility tend to focus on objective measurement, often using journey time as an indicator of spatial separation of people from places. However, using objective measures of spatial accessibility could obscure inequities in accessibility that occur due to differences in perceptions of accessibility among (groups of) individuals. This paper uses data from a case study in Greater Nottingham, UK, to demonstrate that there are differences between self-reported and objective measures of journey time access to destinations. Self-reported journey times to a number of destinations by walking, public transport, and car are compared with a nationally available dataset of accessibility indicators. Then, factors associated with self-reported journey times are investigated to understand what accounts for differences between individual's self-reported understanding and objective measures of journey time accessibility.

Results show that there is a difference between self-reported and objective measures, and that objective measures usually underestimate journey time accessibility. These differences occur because of demographic factors (e.g., age), trip familiarity, and destination definition. If accessibility metrics are to be used to address issues of social inequity related to transport, then there is a need to consider how diverse perceptions of accessibility relate to objective measures and to develop approaches that can account for social as well as spatial variation in accessibility.
\end{abstract}

\section{Article history:}

Received: October 31, 2016

Received in revised form:

April 8, 2018

Accepted: July 15, 2018

Available online: November 29, 2018

Copyright 2018 Angela Curl

http://dx.doi.org/10.5198/jtlu.2018.1003

ISSN: 1938-7849 | Licensed under the Creative Commons Attribution - Noncommercial License 4.0

The Journal of Transport and Land Use is the official journal of the World Society for Transport and Land Use (WSTLUR) and is published and sponsored by the University of Minnesota Center for Transportation Studies. This paper is also published with additional sponsorship from WSTLUR. 


\section{Introduction}

Accessibility to goods and services is an important aspect of quality of life. An inability to access basic services such as employment, education and healthcare can result in transport related social injustice and inequality, an issue which is receiving ongoing attention (Nazari Adli \& Donovan, 2018; Pereira, 2018; Pereira, Schwanen, \& Banister, 2017). Measuring spatial accessibility to destinations is important for understanding whether there are inequalities in accessibility and whether these are spatially and socially patterned. In many countries worldwide there are ongoing attempts to measure accessibility in order to identify gaps and inequalities in the provision of transport services or the distribution of basic services (Nazari Adli, \& Donovan, 2018). An early example of this approach in practice is the process of Accessibility Planning in the UK, a policy mechanism designed to improve the ability of people to access opportunities (Halden, 2011). As part of this policy process a national dataset of accessibility statistics was developed to support decision making and prioritize investment towards areas of need, typically identified as areas falling outside of a threshold of journey time accessibility to key services.

Many approaches to measuring accessibility use journey time as foundation for understanding the physical separation of people and place. However, such spatial accessibility measures, focused on average journey times fail to account for the fact that perceptions and experiences of accessibility will differ from these objective measures. Failing to understand such differences may perpetuate inequalities by excluding those most at the margins, who do not experience "average' accessibility, as objectively measured. While objective measurement may identify inequalities in accessibility between places, in order to understand equity there is also a need to consider how the capabilities (Pereira et al., 2017) of people living in places may vary, impacting their lived experience of accessibility. Differences between how the journey time component of an accessibility model is calculated objectively and how individuals either perceive or experience journey time to particular destinations therefore has implications for equity concerns in transport and land-use planning. While there are many laudable attempts to understand spatial equity through accessibility measurement, this paper questions whether this can be achieved if individual difference within spatial units is ignored.

The need for a greater understanding of perceived accessibility or mobility in relation to objective measures has been noted for many years (Morris, Dumble, \& Wigan, 1979), yet more recent calls for work in this area (Jones, 2011; van Acker, van Wee, \& Witlox, 2010; van Wee, 2016; Ziegler \& Schwanen, 2011) suggest that progress is limited.

There is a tendency for authors to consider perceptions to be "biased" (Vreeswijk, Thomas, van Berkum, \& van Arem, 2014), “distorted” (González, Martínez-Budría, Díaz-Hernández, \& Esquivel, 2015), "inaccurate" (Krizek, 2010) and "misperceived" (Peer, Knockaert, Koster, \& Verhoef, 2014) without acknowledging that perceived, or self-reported, journey times may in fact be a better representation of an individual's reality than any objective measure. Perceptions of accessibility are defined here as how an individual, or groups of individuals, understand or experience their own accessibility. As many accessibility metrics rely on journey time, how an individual perceives their journey time to destinations is an important first step in understanding how perceptions of accessibility might differ from objective measures. Although of course, in some cases people may not estimate time well, it is equally likely that objective measures do not accurately reflect the reality. It is important to understand where objective measurement may be systematically inaccurate and therefore bias assessments of accessibility, potentially leading to inequities for certain groups.

The aim of this paper is to draw attention to the importance of understanding differences between objective and self-reported measures of journey time accessibility from a transport equity perspective, through an empirical investigation journey time accessibility to destinations, addressing a research gap outlined by van Wee (2016). The paper uses data from a case study situated in Nottingham, UK to 
critique objective measures of accessibility used as part of the Accessibility Planning process in the UK and suggest ways in which such objective measures can better reflect experiences and perceptions of accessibility.

\section{Background}

\subsection{Accessibility and equity}

Accessibility is defined as ease of access to destinations (Social Exclusion Unit, 2003) and pertains to the relationship between people, transport and land use. Improving accessibility has long been an aim of transport planners (Holst, 1979; Metz, 2008) and is generally seen as a normative policy goal within transport planning (Farrington \& Farrington, 2005; Ross, 2000). Accessibility is a core concept in studies of transport related social inclusion, equity and justice. Pereira et al., (2017) suggested that prioritizing the needs of disadvantaged groups through the use of accessibility standards is the most appropriate way to address issues of transport equity, a perspective which is broadly consistent with the approach underpinning Accessibility Planning in the UK, which came about following a report by the Social Exclusion Unit (2003). However, determining what accessibility individuals should have (Farrington \& Farrington, 2005) is more difficult in practice and can be further problematized by the fact that existing approaches to measuring accessibility assume homogeneity of perceptions of accessibility. Even if certain disadvantaged groups' accessibility can be prioritized according to spatial measures of accessibility, if this does not relate into how they perceive or experience travel, then it is not clear whether social justice goals can be met. After all, the purpose of ensuring equitable access must surely be to ensure that uptake of services, such as employment, healthcare and education materializes for those disadvantaged groups.

\subsection{Objective measurement of accessibility}

Approaches to measuring accessibility usually focus on the relationship between transport and land use and include measures of the separation of people from places. However, 'people' in this context are generally seen as homogenous and accessibility measures considering individual capabilities are lacking (Pereira et al, 2017). Measures are often aggregate, and analysis is undertaken at the zonal level using Geographical Information Systems (GIS), which assume homogeneity of accessibility among geographical zones, obscuring more scattered instances of inaccessibility, which are likely to be experienced by those most at risk from exclusion (Hine \& Grieco, 2003).

Accessibility measures vary in their complexity, behavioral robustness and practical applicability (for an overview, see Geurs \& van Eck, 2001) but usually include journey time in some way as a measure of physical separation. Where this journey time is not an accurate reflection of the perception, experience or lived reality then spatial accessibility measures may obscure inequality of access. In general, measures used by planners typically focus on the time taken to the nearest destination, or the number of opportunities of a given type accessible within a given time threshold (cumulative opportunity measures). Beyond whether the measures are an accurate reflection of perceptions of journey time, such measures can be problematic when considering equity because, for example, of the appropriateness of destinations included, or the cost of travel. However, the focus here is on whether the assumptions of homogeneity of travel time among individuals living in the same place are problematic.

For example, consider the target, taken from one municipality's accessibility strategy, to ensure that " $45 \%$ of the population aged over 65 have access to a doctor's surgery within 15 minutes". Using an accessibility model based on average walk speed it might be calculated that the target has been met. However, while $45 \%$ of the older population may have access according to the model, because older adults' experienced journey times are longer than average, the model overestimated their level of accessi- 
bility. By assuming population heterogeneity, objective measures of accessibility are open to entrenching inequities in accessibility, even when they aim to target accessibility for a particular group, who may be identified as disadvantaged. In such cases, this could be overcome through weighting the assumptions in the model to account for the needs of the particular target group, but doing so requires more understanding of how different groups perceive accessibility.

In contrast to an objective measure of accessibility, perceived accessibility also accounts for how accessible places are from the perspective of an individual. Perceived accessibility is more likely to influence behaviors (Morris et al., 1979; Wang, Brown, Liu, \& Mateo-Babiano, 2015), in terms of travel or accessing services. Objective measures can fail to represent perceptions accessibility in two ways. Firstly, not only time is important in determining how an individual perceives their level of access to any given (set of) destinations: issues such as cost, frequency, quality, comfort and so on are harder to incorporate into accessibility models. Secondly, even if time is the focus how individuals perceive or experience accessibility is likely to differ from an objective measure. The time component is the focus of this paper, although there is also a need to concentrate on non-time aspects of accessibility in future research.

Where perceived accessibility differs from objective measures the reasons need to be understood, otherwise basing policy decisions on objective measures are likely to perpetuate inequalities and exclusion from activities by ignoring the reasons why some people do not or cannot access destinations, despite having an 'acceptable' level of access according to objective measures.

Although non-time based aspects of accessibility are frequently recognized by planners (Curl, Nelson, \& Anable, 2011), time is a concept that is easier to understand and can be measured more easily. As a result time based accessibility measures dominate current approaches in transport planning, although there are exceptions (Curtis \& Scheurer, 2016). Non-time aspects of accessibility are particularly important for understanding perceptions of accessibility, but the starting point in this paper is to demonstrate, that, even when using time based measures there are important differences between perceived and objective measures and that this has important equity implications.

\subsection{Existing studies of objective and perceived accessibility}

There are several studies comparing self-reported and objective journey times. Most studies find that self-reported measures over-estimate compared to objective measures (Curl, Nelson, \& Anable, 2015; González et al., 2015; Krizek, Horning, \& El-Geneidy, 2012; Vreeswijk et al., 2014) although there are exceptions (Delclòs-Alió, Marquet, \& Miralles-Guasch, 2017). Reasons for these differences vary, but include people factors and environmental factors (Krizek et al., 2012) such as demographic characteristics, familiarity with a trip, or pleasantness of the urban environment. There is a tendency for selfreported times to be greater for modes or routes not chosen by participants (van Exel \& Rietveld, 2009; Vreeswijk et al., 2014), linked to trip familiarity.

Lotfi and Koohsari, (2009) use three objective measures (Infrastructure, Activity and Utility based) and compare these with an approach based on interview and questionnaire data. They find that those areas with the highest objective accessibility are not perceived as such by residents (in terms of satisfaction with access to facilities) due to issues of safety and security. Ball et al., (2008) compared objective, GIS based measures of accessibility to physical activity facilities such as leisure centers or outdoor space with self-reported accessibility based on whether a respondent said a facility was within walking distance of their home and found agreement was low, particularly for certain demographic groups.

McCrea, Shyy, and Stimson, (2006) compared a range of objective and subjective measures of urban quality of life, including access, and found that agreement was low. They suggest caution in assuming that improving objective accessibility through changes to the built environment will also lead to changes in perceptions. Gebel, Bauman, Sugiyama, and Owen (2011) undertook a longitudinal 
study into the relationship between objective and perceived measures of neighborhood walkability and changes in walkability and Body Mass Index (BMI) over a four year period. They found that a third of those who lived in a neighborhood objectively measured as highly walkable, perceived it as low in terms of walkability, and vice versa, a third of those living in low walk neighborhoods perceived them as walkable. Furthermore they found that individuals who had a mismatch between perceived and objectively measured walkability (where perception was low compared to objective measure) reduced their walking for transport and leisure, and increased their BMI significantly more over the four year period than those with a greater agreement between objective measures and perceptions.

While there is a considerable body of work attempting to develop objective measures of accessibility and equally those seeking to understand people's perceptions and experiences of travel (Lättman, Olsson, \& Friman, 2016), there is limited work directly comparing the two approaches to understanding accessibility for the same people or places. If more can be done to understand the difference between perceived and measured accessibility, then improvements in perceived and therefore realized accessibility, may be achieved, alongside improvements in how accessibility is measured and assessed by practitioners.

If those people who do not perceive accessibility to be the same as it is measured objectively are likely to experience worse than expected outcomes, then it is important to think about whose assumptions are reflected in objective measures and what the likely implications of these assumptions will be. If some demographic groups are less likely than others to show concordance with objective measures then this raises an issue of how representative an objective measure is for different population groups and any policy based on such objective measures may therefore lead to an uneven distribution of outcomes, because objective measures may prioritize the needs of some groups over others. It is important to remember here, that perceptions relate to how individuals understand their own accessibility. This may differ from an objective measure because of "misperception"(Peer et al., 2014), as has been noted, but also because the experience or reality of accessibility is not well represented by an objective measure. In such cases, allocating resources according to objective measures could be considered inequitable as it does not adequately account for the accessibility of all groups.

It is therefore hypothesized that perceived accessibility will vary from typical objective measures for two principal reasons. Firstly, objective measures may not be an accurate representation of how people understand their own accessibility because the parameters do not represent the needs of the population group. Secondly, and more commonly explained is that individuals do not have a complete understanding of the potential accessibility, for example because of a lack of information about a transport service.

\section{Research approach}

This study is an empirical contribution demonstrating differences in perceived and objective measures of journey time accessibility using a case study based in Nottingham, UK. The policy context for this research is Accessibility Planning in the UK, which was designed to address issues of transport related social exclusion. On this basis, the objective measures used in the paper are taken from a nationally available dataset of accessibility indicators. The objective measures are described in more detail below. While more robust objective measures do exist and could have been developed, the purpose here was to situate the work in the context of measures being used to support the Accessibility Planning process in the UK. Therefore, while some of the critique of objective measures in this paper can be generalized, in many ways it is specific to these measures. Accessibility Planning sought to address multiple barriers to accessibility (including time, safety, cost) but this recognition was not translated into measures of accessibility and a focus on time based measures remained (Curl et al., 2011). While there was a focus on typically excluded groups such as those on low incomes or older adults, given the spatial nature of accessibility measurements, issues of inaccessibility for such groups would only be highlighted where a concentration 
of a particular grouped lived in an area of poor accessibility. Differential perceived access for these groups may mean that inequalities in accessibility are deeper than suggested by objective measurement.

\subsection{Data}

A household survey was sent to 2400 households in the Greater Nottingham (UK) area in November 2010, in order to elicit perceptions of accessibility which could then be compared with a national dataset of objective measures of accessibility - the Core Accessibility Indicators (CAI). A sample frame was selected using a multi stage cluster sampling process. Sample areas were stratified according to objective accessibility measures, indices of multiple deprivation (IMD) and mode of travel to work (Census, 2001). A combination of the Royal Mail Postcode Address File (PAF) and the edited electoral register was then used to select individual households. The response rate was $14 \%(\mathrm{n}=328)$. Table 1 details the characteristics of the sample compared with the Greater Nottingham and England population.

The questionnaire asked questions relating to: travel activity; overall perceptions and satisfaction with accessibility in the local area; perceived journey times to a number of destinations; ratings of key aspects of accessibility; and demographic information.

Perceived journey time accessibility is measured using self-reported journey times to destinations. Survey respondents were asked how long it would take them to travel to each of seven different destination types (doctor, hospital, supermarket, primary school, secondary school, college and city center) by walking, public transport and by car. They were asked to name the destination, to indicate whether it was their nearest and frequency of use.

In order to be comparable with the CAI only those using their nearest destination were included in the analysis. CAI measures the mean journey time from each Lower Super Output Area (LSOA) to the nearest destination of each type.

Table 1: Sample characteristics

\begin{tabular}{|c|c|c|c|c|}
\hline & & Sample Area & Greater Nottingham & England \\
\hline Number of responses & & 328 & & \\
\hline Response Rate & & $14 \%$ & & \\
\hline Population (2001 Census) & & 12,142 & 703,331 & $49,138,831$ \\
\hline Population (2009 mid-year estimates) & & 13,469 & 753,133 & $51,809,741$ \\
\hline \multicolumn{5}{|l|}{ Sex } \\
\hline \multirow[t]{2}{*}{ Male } & sample & $41 \%$ & & \\
\hline & population & $49 \%$ & $50 \%$ & $49 \%$ \\
\hline \multirow[t]{2}{*}{ Female } & sample & $59 \%$ & & \\
\hline & population & $51 \%$ & $50 \%$ & $51 \%$ \\
\hline \multirow[t]{2}{*}{ Average Age } & sample & 54.8 & & \\
\hline & population & 46.9 & 46.4 & 47.3 \\
\hline \multicolumn{5}{|l|}{ Household Car ownership } \\
\hline \multirow[t]{2}{*}{ No car. } & sample & $22 \%$ & & \\
\hline & population & $32 \%$ & $31 \%$ & $27 \%$ \\
\hline \multirow[t]{2}{*}{$1 \mathrm{car}$} & sample & $47 \%$ & & \\
\hline & population & $44 \%$ & $44 \%$ & $44 \%$ \\
\hline \multirow[t]{2}{*}{$2 \mathrm{car}$} & sample & $28 \%$ & & \\
\hline & population & $20 \%$ & $20 \%$ & $24 \%$ \\
\hline \multirow[t]{2}{*}{$3+c a r$} & sample & $4 \%$ & & \\
\hline & population & $4 \%$ & $4 \%$ & $6 \%$ \\
\hline
\end{tabular}


The CAI were selected as a national dataset designed to be used by transport planners and other sectors to measure spatial and temporal variation in accessibility in the UK. Measures were calculated for drive and public transport journeys. The measures include door to door journey times, accounting for walk time as part of a public transport journey, wait times and parking time, but did not include walk-only measures. The CAI measures are geographically weighted means for the smaller output areas (OA) within a LSOA. Therefore as the survey responses represent a random sample of the population within each LSOA the mean of survey responses is hypothetically the same as the CAI geographically weighted mean. The CAI report an average journey time throughout the day, whereas the survey responses relate to a journey to arrive at $9 \mathrm{am}$. However the CAI average measures are heavily weighted towards peak time journeys to reflect usage patterns (DfT, 2009), and this was therefore the most realistic time to use in the questionnaire.

\subsection{Analysis}

Firstly differences between objective measures and self-reported journey times are explored at an aggregate level to gain an understanding of the direction of the differences by destination and by mode.

Then multivariate linear regression models are estimated to identify factors other than objective journey time explaining variation in reported journey time. In this analysis the dependent variable is self-reported journey times provided by respondents in the household survey. Separate regression models were used to explain reported journey time for each mode and destination type.

Blocked regressions were undertaken to first confirm the percentage variance in individuals' reported journey times explained by the objective measures and then to explore the additional variance (if any) that can be explained by other variables controlling for objective measures of accessibility. Using blocked regressions allows different variables to be added, identifying their additional contribution to the outcome variable. It also means the additional $\mathrm{R} 2$ achieved by adding variables is clear, removing problems usually associated with multi-collinearity such as difficulties identifying which variables are contributing to explaining the variance and clearly highlights the contribution of variables both individually and together.

Objective journey time is an important explanatory variable for this analysis. Firstly because it is likely to account for a significant proportion of the variation in individuals' reported journey times and secondly because when exploring the influence of other explanatory variables it is important to control for objective journey times first of all. For example, a certain demographic group may report longer journey times to a destination but it is first necessary to account for the fact that they may live in an area with longer journey times.

Additional variables were selected on the basis being correlated with self-reported journey time in bivariate analyses or based on evidence from previous research. The frequency of going to a destination and mode of transport used are included to account for familiarity. It is expected that those familiar with a particular trip may report journey times that are closer to an objective measure (van Exel \& Rietveld, 2009). Age and gender are likely to have an impact on travel choices and perceptions. Furthermore personal car availability is included, as the car is found to be a reference point for perceptions of accessibility so those with a car available may perceive journey times differently to those who do not. The control variable is slightly different for walk journey times as a CAI measure is not available for walking. For walk journey times objective accessibility is controlled for using a binary variable of accessible or not accessible based on the Indices of Multiple Deprivation (IMD). 


\section{$4 \quad$ Results}

\subsection{Comparison of objective and self-reported journey time to destinations}

This section presents a comparison of journey time measures to the nearest destination as measured by the CAI and as reported by survey respondents for Public Transport (PT) and car.

Figure 1 summarizes the ratio of survey reported journey times to objective measures by mode and destination at an aggregate level.

The ratio is positive across all modes and destinations showing that self-reported journey times are greater than objective measures, in aggregate.

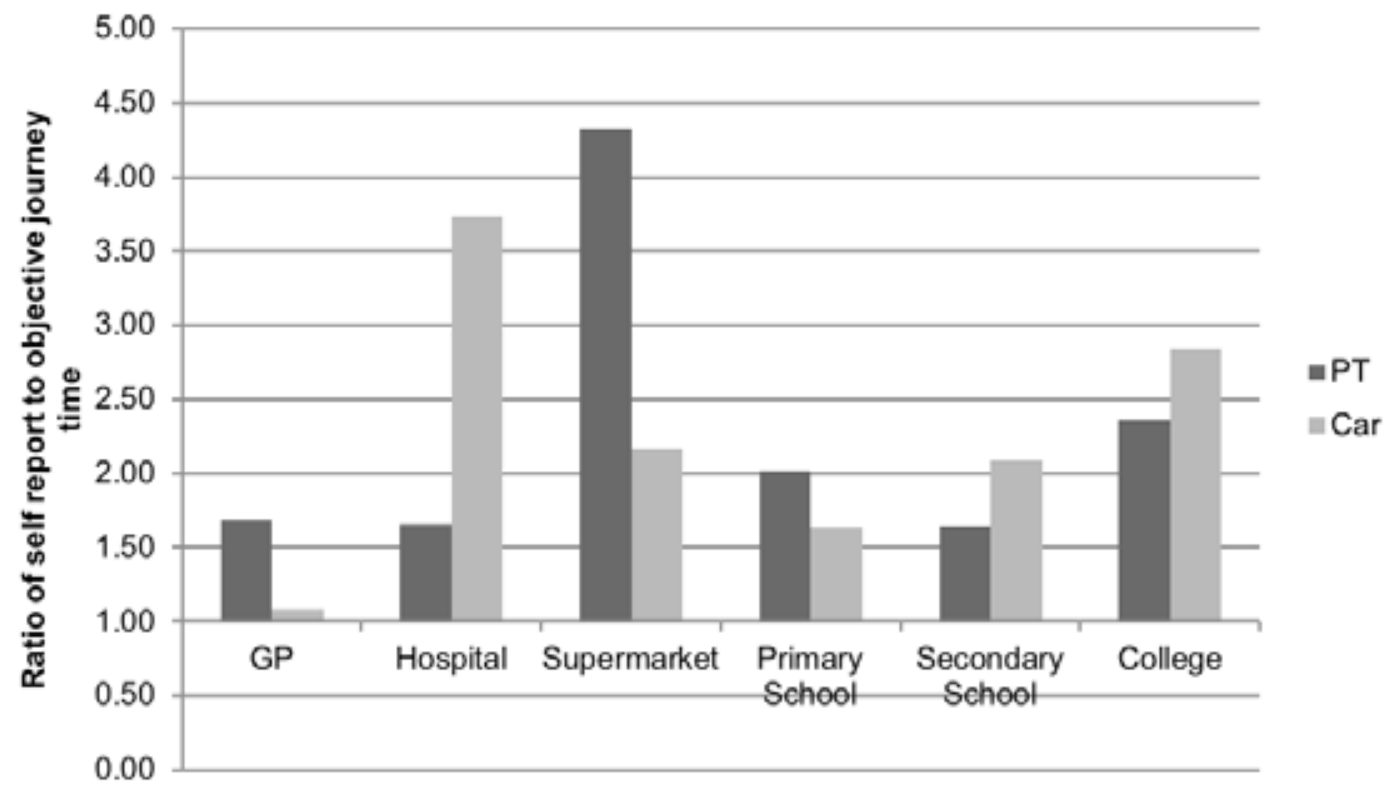

Figure 1: Ratio of self-reported to objective measures of journey time to destinations. If $y=1$ then the values are equal, if $y=5$, self-reported measures are 5 times greater than objective measures. The graph shows that in all cases self-reported journey times are greater than objective measures.

In the majority of cases differences in car journey times are smaller than for public transport journey times. The mean difference is almost 20 minutes for some PT journey times, notably to hospitals and supermarkets implying that perceptions and CAI measures differ more greatly for these destinations. This suggests either that the survey responses overestimate the time taken, or that objective measures under-calculate the time taken for the individual. These findings are consistent with the existing literature (Curl et al., 2015; González et al., 2015; Krizek et al., 2012; Vreeswijk et al., 2014).

It could be argued that survey responses could be greater than CAI measures due to rounding of survey responses, for example it is unlikely that somebody would report an 8 minute journey time, but rather round it up to 10 minutes. However, this does not seem to be a valid argument as rounding tends to work in both directions and has been shown not to affect results overall in a study comparing self-reported and measured distance (Witlox, 2007). Another reason is that different factors will be considered in each measure, for example the objective measure does include parking time, but may not accurately account for congestion, or bus service reliability, which people may factor into reported journey times. Inaccuracy in objective measures is one of the key explanations for differences between the two types of measure. Where they affect everyone evenly this is less problematic but if such discrepancies are unevenly distributed socially or spatially then some will be affected more than others by an 
objective measure which does not accurately reflect experiences of accessibility. The following section explores factors that are associated with self-reported journey times to destinations, after controlling for objective journey times.

\subsection{Explaining self-reported journey times}

This section develops understanding of what explains self-reported journey times other than the measurable journey time so that it can be highlighted where certain groups of people may not be well represented by aggregate accessibility measures. While the differences between objective and self-reported measures found in the previous section are to be expected (Pacione, 1982), understanding for whom and where differences occur is crucial if measures are to better reflect diverse experiences of accessibility.

Table 2 shows regression results by mode and destination. As expected, objective journey time contributes significantly to the explanation of variance in the self-reported journey time in most cases. In all cases adding demographic variables to the model in Block 2 resulted in a much higher R2, meaning that the additional factors explain more of the variance in reported journey times than when using objective journey time alone.

Those that use public transport to access hospitals report shorter public transport journey times than those that don't, suggesting that familiarity and experience with this journey means shorter reported journey times. Those that visit the doctors more often report longer walk journey times. Although the model controls for age and disability it could be that those that visit the doctors more often are more likely to be in poorer health and take longer to walk, or that they are usually transported to the doctors and are unfamiliar with how long it would take to walk.

Those with a reported disability reported longer car journey times to doctors, longer walk journey times to primary schools and longer journey times for all modes to secondary school. Age is a significant explanatory variable for reported PT and car journey times to supermarkets and for car journeys to hospitals. Older people report longer journey times, after controlling for objective journey times. Even if older people in the sample live in a more inaccessible area they report longer journey times than younger people living in the same area. This is expected as older people may have reduced physical mobility and therefore experience longer journeys.

Those with a car available report longer walk times to secondary school and public transport times to colleges. This could be because those who have a car travel further to these destinations, or because they perceive the same walk more negatively given their comparison with car times.

The negative relationship between reported journey times and CAI measures for car journeys to supermarkets is unexpected. Those that drive to the supermarket report longer journey times by car than non-car users after controlling for objective journey time. Furthermore, those with a car available report longer public transport and walk journey times than those without a car. Although this analysis uses only respondents who said they were using their nearest supermarket, the mean (straight line) distance travelled to a supermarket is 2.11 (SD 3.4) miles for car users compared to 0.59 (SD 1.4) miles for non-car users $(\mathrm{t}=-6.319, \mathrm{p}<0.01)$. This means that car users travel further to the supermarket, despite both car and non-car users describing the supermarket listed as their nearest. This suggests a difference in perception of what constitutes a supermarket for car and non-car users. While for a car user the nearest may be a large out of town supermarket, for non-car users more local stores are considered in their subjective choice sets.

In summary, after controlling for objective measures, demographic variables, particularly age and car availability, are useful in contributing to understanding reported journey times. The influence of demographic variables ranges across destinations. It is therefore clear that self-reported journey times differ from objective measures. 
Table 2: Factors associated with self-reported journey time by destination and mode. First block shows the association between objective journey time and self-reported measures. Second block shows additional factors associated with self-reported journey time accessibility to destinations.

\begin{tabular}{|c|c|c|c|c|c|c|c|c|c|}
\hline \multirow{2}{*}{$\begin{array}{l}\text { Predictors } \\
\text { Block } 1\end{array}$} & \multicolumn{3}{|c|}{ Supermarket } & \multicolumn{3}{|c|}{ Hospital } & \multicolumn{3}{|c|}{ Doctors } \\
\hline & $\begin{array}{c}\text { PT } \\
(n=144)\end{array}$ & $\begin{array}{c}\text { Car } \\
(n=211)\end{array}$ & $\begin{array}{c}\text { Walk } \\
(\mathbf{n}=190)\end{array}$ & $\begin{array}{c}\text { PT } \\
(n=240)\end{array}$ & $\begin{array}{c}\text { Car } \\
(n=245)\end{array}$ & $\begin{array}{c}\text { Walk } \\
(n=145)\end{array}$ & $\begin{array}{c}\text { PT } \\
(n=98)\end{array}$ & $\begin{array}{c}\text { Car } \\
(n=215)\end{array}$ & $\begin{array}{c}\text { Walk } \\
(n=244)\end{array}$ \\
\hline $\mathrm{r}^{2}$ & .028 & .180 & .263 & .090 & .220 & .157 & .051 & .003 & .034 \\
\hline$F$ & 4.041 & 45.996 & 66.955 & 23.506 & 69.584 & 26.641 & .252 & .655 & 8.537 \\
\hline Objective JT Accessibility (CAI) & $.166^{*}$ & $-.425^{* *}$ & $-.512^{* *}$ & -.300 & $.401^{* *}$ & $-.396^{* *}$ & .051 & .055 & $-.185^{* *}$ \\
\hline \multicolumn{10}{|l|}{ Block 2} \\
\hline$r^{2}$ & .187 & .308 & .343 & .191 & .264 & .213 & .269 & .078 & .216 \\
\hline$F$ & 4.476 & 12.905 & 13.572 & 7.809 & 12.369 & 5.306 & 1.003 & 2.502 & 9.270 \\
\hline Objective JT Accessibility (CAI) & $.245^{* *}$ & $-.382^{* *}$ & $-.494^{* *}$ & -.318 & $.399^{* *}$ & $-.387^{* *}$ & .069 & .071 & $-.117^{*}$ \\
\hline Age & $.228^{* *}$ & $.203^{* *}$ & -.069 & .238 & $0.39^{*}$ & .036 & -.128 & -.005 & -.015 \\
\hline Frequency of going to destination & .023 & -.102 & .04 & -.027 & .050 & -.122 & -.004 & .059 & $.157^{*}$ \\
\hline PT user (to destination) ${ }^{\mathrm{a}}$ & -.056 & - & - & $-.167^{*}$ & - & - & .110 & - & - \\
\hline Car user (to destination) ${ }^{a}$ & - & $.233^{*}$ & - & - & .104 & - & - & .023 & - \\
\hline Walks to destination ${ }^{a}$ & - & - & $-.158^{*}$ & - & - & -.046 & - & - & $-.382^{* *}$ \\
\hline Gender ${ }^{\mathrm{b}}$ & .077 & .009 & -.035 & -.060 & $1.221^{*}$ & -.073 & $.020^{*}$ & -.065 & .022 \\
\hline Disability ${ }^{c}$ & .038 & .044 & .034 & .059 & .435 & .120 & .231 & $.237^{* *}$ & .072 \\
\hline Car Availability $^{d}$ & $.281^{\wedge}$ & .034 & $.175^{*}$ & .083 & .025 & .150 & .056 & -.049 & -.009 \\
\hline Predictors & \multicolumn{3}{|c|}{ Primary School } & \multicolumn{3}{|c|}{ Secondary School } & \multicolumn{3}{|c|}{ College } \\
\hline Block 1 & $\begin{array}{c}\text { PT } \\
(n=52)\end{array}$ & $\begin{array}{c}\text { Car } \\
(n=137)\end{array}$ & $\begin{array}{c}\text { Walk } \\
(n=161)\end{array}$ & $\begin{array}{c}\text { PT } \\
(\mathbf{n}=\mathbf{8 0})\end{array}$ & $\begin{array}{c}\text { Car } \\
(n=139)\end{array}$ & $\begin{array}{c}\text { Walk } \\
(n=142)\end{array}$ & $\begin{array}{c}\text { PT } \\
(n=87)\end{array}$ & $\begin{array}{c}\text { Car } \\
(n=115)\end{array}$ & $\begin{array}{c}\text { Walk } \\
(\mathrm{n}=91)\end{array}$ \\
\hline$r^{2}$ & .000 & .000 & .029 & .092 & .051 & .356 & .022 & .119 & .114 \\
\hline$F$ & .001 & .012 & 4.777 & 7.909 & 7.395 & 77.253 & 1.901 & 15.241 & 11.483 \\
\hline CAI journey time & -.003 & .009 & $-.171^{*}$ & $.303^{* *}$ & $.226^{* *}$ & $-.596^{* *}$ & .148 & $.345^{* *}$ & $-.338^{* *}$ \\
\hline \multicolumn{10}{|l|}{ Block 2} \\
\hline$r^{2}$ & .056 & .049 & .155 & .216 & .149 & .475 & .173 & .214 & .219 \\
\hline$F$ & .376 & .955 & 4.021 & 2.833 & 3.270 & 17.346 & 2.359 & 4.168 & 3.316 \\
\hline CAI journey time & -.023 & .025 & $-.156^{*}$ & $.306^{* *}$ & $.250^{* *}$ & $-.567^{* *}$ & .142 & $.335^{* *}$ & $-.322^{* *}$ \\
\hline Age & .017 & .023 & -.061 & .169 & .175 & -.075 & .221 & .172 & .066 \\
\hline Frequency of going to destination & .063 & -.029 & $.442^{* *}$ & .052 & -.031 & .124 & $.247^{*}$ & -.025 & $.288^{* *}$ \\
\hline PT user (to destination) $)^{\mathrm{a}}$ & .013 & - & - & -.032 & - & - & -.130 & - & - \\
\hline Car user (to destination) ${ }^{a}$ & - & 0.68 & - & - & .086 & - & - & .180 & - \\
\hline Walks to destination ${ }^{a}$ & - & - & $-.414^{* *}$ & - & - & -.138 & - & - & $-.244^{*}$ \\
\hline Gender $^{\mathrm{b}}$ & .092 & .033 & $.143^{\wedge}$ & -.158 & -.046 & -.081 & .048 & -.084 & -.024 \\
\hline Disability & .039 & $.182^{*}$ & $.163^{*}$ & $.247^{*}$ & $.213^{*}$ & $.289^{* *}$ & -.155 & .007 & .075 \\
\hline Car Availability ${ }^{\mathrm{d}}$ & .195 & -.075 & .042 & .090 & .052 & $.189^{* *}$ & $.210^{*}$ & .194 & .144 \\
\hline
\end{tabular}

\section{$5 \quad$ Discussion and conclusions}

It is clear from the results that there are differences between objective and self-reported journey time measures. In most cases the objective measures were lower than the self-reported reported journey times as has been found in previous research (Curl et al., 2015; González et al., 2015; Krizek et al., 2012; Vreeswijk et al., 2014). This paper has shown this is true across a wide range of modes and destinations, 
while also demonstrating variation by mode and destination. Furthermore, this paper has highlighted how such differences can be an issue in studies of transport equity.

Differences vary by mode. In general there is less difference between self-reported and objective journey times for car than public transport. Differences between objective and self-reported measures of journey time accessibility tend to be larger for public transport journey times whereas measures are more similar for car journey times, similar to the findings of van Exel \& Rietveld (2009).

There is also variation by destination. Differences are larger for supermarkets and hospitals than other destinations which may be as a result of issues of definition of these destinations or because they are usually more distant. Similar to Krizek et al., (2012) the reasons for differences between objective and self-report measures in this study may be because of destination definition. The fact that different mode users had varying definitions of a supermarket highlights the importance of considering subjective choice sets in accessibility analyses, a point supported by van Wee, (2016). It is important to consider which destinations people perceive as accessible to them and further work is needed to understand how subjective choice sets may influence accessibility. According to some definitions, accessibility includes not only spatial access, but also availability, affordability, acceptability and accommodation (Caspi, Sorensen, Subramanian, \& Kawachi, 2012; Humphreys \& Smith, 2009) which consider how appropriate particular services are to users' needs.

Differences can occur either because objective measures do not reflect the lived experience of different social groups very well or as a result of misperceptions. Objective measures of spatial accessibility are an inaccurate reflection of the lived reality when assumptions are made regarding the constraints or choices of individuals which do not apply equally across the population. In this case, for a particular individual or group of people, (e.g., older adults) accessibility is worse than for the average upon which an accessibility measure is calculated. On the other hand, differences may occur due to lack of knowledge of survey respondents (Krizek et al., 2012) which could be shaped by their experience. This might occur, because an individual's attitudes or lifestyle (e.g., car user) means that they perceive accessibility differently. This does not necessarily mean that their perception is "wrong", but that familiarity with journeys by particular modes or to particular places is another reason for perceptions differing from objective measures. This is related to travel horizons, which were identified as a barrier to accessibility by the Social Exclusion Unit (2003). An individual's perception of accessibility may be different to that suggested by an objective measure because of their travel horizons: a lack of awareness, familiarity, experiences or trust of transport services or destinations.

The two reasons identified for differences between objective measures and perceptions of journey time each lead to very different policy responses to improve accessibility. If a certain demographic group perceives or experiences accessibility differently to that which is measured for the population, then measures might be put in place to support accessibility for a particular sub-group, such as subsidized transport or door to door shuttle services for hospital appointments. Familiarity with modes was also highlighted as a reason for differences between perceptions and objective measures, for example, car users who report longer PT journey times probably do so because of lack of experience. In such cases, perceived accessibility could be changed, for example through information and education campaigns.

Perceptions of accessibility are related to both environmental conditions and individual attributes. It is therefore important that measures of accessibility can recognize social as well as spatial variation. The fact that some socio-demographic groups are more likely than others to perceive or experience accessibility differently to existing objective measures, means that the needs of such groups are not reflected in objective measures. Therefore, if policy or planning decisions are made on the basis of such measures then they are likely to lead to exclusion of some groups and perpetuate existing inequities in realized accessibility.

Either objective or perceived measures in isolation are problematic in equity terms. If two are as- 
sumed to be a proxy for one another then transport and social policies may not have the desired impacts on behavior and wider outcomes such as social equity.

Accessibility measures could be weighted to account for population characteristics based on census data and further research to define appropriate parameters for different social groups.. An example of this is older adults who have been found to report longer journey times. It is clear that this is because this population group is likely to move at a different speed and therefore standard accessibility measures would overestimate the level of accessibility within any given time threshold. If accessibility measures could be weighted to account for variation in population then measures might be a better reflection of realized accessibility. This might include representing heterogeneity and uncertainty more explicitly in traditional accessibility metrics.

While there is a normative view that there should be a minimum provision of service or level of inclusion (Farrington \& Farrington, 2005; Pereira, et al., 2017), defining what this is, is more difficult (Pereira et al., 2017), especially when perceptions are taken into account. Any attempt to measure accessibility should consider the purpose of doing so and ensure the measure adopted is appropriate. If regional planning is the main imperative then spatial accessibility measures such as the CAI may be appropriate. However, if the main outcomes are related to individuals, issues of travel behavior, justice and equity then measures which account for diversity of perceptions and experiences need to be developed. While accessibility is a geographical problem, it is also a social one, so two people in the same place may experience different "accessibilities" (Handy \& Niemeier, 1997). A given level of accessibility 'provision' may be acceptable for one person yet not for another living in the same building as demonstrated by the results shown here and by Farrington, who explains: "a place is not just 'more' or 'less' accessible, but accessible relative to people in all their different circumstances; people experience more, or less access to places" (Farrington, 2007, p.320). Equally the same person will experience different accessibility dependent upon the place they are in at any given time and changing constraints and mobility across the life-course.

The measurement of accessibility is an important aspect of transport studies which has traditionally been dominated by objective spatial measurement. This paper challenges the dominant approach and demonstrates the need to ensure perceptions are considered if equity is a concern. It adds to understanding of how objective and self-reported measures compare, which, while being researched in other fields (Kuz, 1978; Pacione, 1982) has not been widely studied for accessibility to destinations.

The choice of modes and destinations is informed by those used as part of the accessibility planning process in the UK, but may not reflect those which are important in all contexts or cultures, or for individuals. Using more spatially detailed objective measures of accessibility would strengthen future research. Technological advances in the few years since this research was undertaken mean there is now huge scope for more innovative approaches to understanding perceived accessibilities, for example through crowdsourcing, and at the same time greater potential for improvements in calculation of accessibility measures using open-source data such as the Google Transit Data Feed.

This paper has demonstrated the potential for and importance of differences between perceived and objective journey time accessibility at a basic level. Further work is needed to understand factors beyond journey time which are important in determining perceptions of accessibility, such as safety, cost, or capabilities and how these might compare to more sophisticated measures of accessibility. It is acknowledged that more behaviorally robust models of accessibility do exist and future work could investigate whether these better represent perceptions of accessibility for different socio-demographic groups.

While measurement of accessibility is important and can help advance transport justice and reduce inequalities, it is important to consider how this varies, both spatially and socially. Considering how measures of accessibility can better reflect heterogeneity of perceived accessibility is crucial in order to address transport equity. 


\section{Acknowledgements}

The results published in this paper have previously been published as part of a PhD Thesis: Curl, A (2013) Does Accessibility Planning address what matters? Comparing the lived experience to objective measures of accessibility. University of Aberdeen. DOI: 10.13140/RG.2.1.3374.3601

The author would like to acknowledge the advice and support of $\mathrm{PhD}$ supervisors, Professor John Nelson and Professor Jillian Anable, who provided guidance for thesis in which the empirical results reported in this paper were original reported. I would also like to thank three anonymous reviewers whose feedback and perseverance have been incredibly helpful in developing and strengthening the arguments in this paper. 


\section{References}

Ball, K., Jeffery, R. W., Crawford, D. A., Roberts, R. J., Salmon, J., \& Timperio, A. F. (2008). Mismatch between perceived and objective measures of physical activity environments. Preventive Medicine, 47, 294-298.

Caspi, C. E., Sorensen, G., Subramanian, S. V., \& Kawachi, I. (2012). The local food environment and diet: A systematic review. Health \& Place, 18(5), 1172-1187. doi.org/10.1016/j.healthplace.2012.05.006

Curl, A., Nelson, J. D., \& Anable, J. (2015). Same question, different answer: A comparison of GISbased journey time accessibility with self-reported measures from the National Travel Survey in England. Computers, Environment and Urban Systems, 49, 89-67. doi.org/10.1016/j.compenvurbsys.2013.10.006

Curl, A., Nelson, J. D., \& Anable, J. (2011). Does accessibility planning address what matters? A review of current practice and practitioner perspectives. Research in Transportation Business \& Management, 2, 3-11. doi.org/10.1016/j.rtbm.2011.07.001

Curtis, C., \& Scheurer, J. (2016). Planning for public transport accessibility: An international sourcebook. Abingdon, UK: Routledge.

Delclòs-Alió, X., Marquet, O., \& Miralles-Guasch, C. (2017). Keeping track of time: A smartphonebased analysis of travel time perception in a suburban environment. Travel Behavior and Society, 9, 1-9. doi.org/10.1016/J.TBS.2017.07.001

DfT. (2009). 2008 Core accessibility indicators. Retrieved from http://www.dft.gov.uk/pgr/statistics/ datatablespublications/ltp/coreaccessindicators2008

Farrington, J., \& Farrington, C. (2005). Rural accessibility, social inclusion and social justice: Towards conceptualization. Journal of Transport Geography, 13(1), 1-12.

Farrington, J. H. (2007). The new narrative of accessibility: Its potential contribution to discourses in (transport) geography. Journal of Transport Geography, 15(5), 319-330.

Gebel, K., Bauman, A. E., Sugiyama, T., \& Owen, N. (2011). Mismatch between perceived and objectively assessed neighborhood walkability attributes: Prospective relationships with walking and weight gain. Health and Place, 17, 519-524.

Geurs, K. T., \& van Eck, J. R. R. (2001). Accessibility measures: Review and applications. Evaluation of accessibility impacts of land-use transportation scenarios, and related social and economic impact (RPRT). RIVM report 408505 006. Bilthoven, Netherlands: National Institute of Public Health and the Environment.

González, R. M., Martínez-Budría, E., Díaz-Hernández, J. J., \& Esquivel, A. (2015). Explanatory factors of distorted perceptions of travel time in tram. Transportation Research Part F: Traffic Psychology and Behavior, 30, 107-114. doi.org/10.1016/j.trf.2015.02.006

Halden, D. (2011). The use and abuse of accessibility measures in UK passenger transport planning. Research in Transportation Business \& Management, 2, 12-19.

Handy, S. L., \& Niemeier, D. A. (1997). Measuring Accessibility: An exploration of issues and alternatives. Environment and Planning A, 29, 1175-1194.

Hine, J., \& Grieco, M. (2003). Scatters and clusters in time and space: Implications for delivering integrated and inclusive transport. Transport and Social Exclusion, 10(4), 299-306.

Holst, O. (1979). Accessibility as the objective of public transportation planning: An integrated transportation and land-use model. European Journal of Operational Research, 3(4), 267-282.

Humphreys, J. S., \& Smith, K. B. (2009). Healthcare accessibility. International Encyclopedia of Human Geography, (pp. 71-79). doi.org/10.1016/B978-008044910-4.00337-0 
Jones, P. (2011). Developing and applying interactive visual tools to enhance stakeholder engagement in accessibility planning for mobility disadvantaged groups. Research in Transportation Business \& Management, 2, 29-41.

Krizek, K. J. (2010). Measuring accessibility: Prescriptions for performance measures of the creative and sustainable city. International Journal of Sustainable Development, 13(1-2), 149-160.

Krizek, K. J., Horning, J., \& El-Geneidy, A. (2012). Perceptions of accessibility to neighborhood retail and other public services. In K. T. Geurs, K. J. Krizek, \& A. Reggiani (Eds.), Accessibility analysis and transport planning: Challenges for Europe and North America (pp. 96-117). Cheltenham, England: Edward Elgar.

Kuz, T. J. (1978). Quality of life, an objective and subjective variable analysis. Regional Studies, 12(4), 409-417.

Lättman, K., Olsson, L. E., \& Friman, M. (2016). Development and test of the perceived accessibility scale (PAC) in public transport. Journal of Transport Geography, 54, 257-263. doi.org/10.1016/j. jtrangeo.2016.06.015

Lotfi, S., \& Koohsari, M. (2009). Analyzing accessibility dimension of urban quality of life: Where urban designers face duality between subjective and objective reading of place. Social Indicators Research, 94(3), 417-435.

McCrea, R., Shyy, T.-K., \& Stimson, R. (2006). What is the strength of the link between objective and subjective indicators of urban quality of life? Applied Research in Quality of Life, 1, 79-96.

Metz, D. (2008). The myth of travel time saving. Transport Reviews, 28(3), 321-336.

Morris, J. M., Dumble, P. L., \& Wigan, M. R. (1979). Accessibility indicators for transport planning. Transportation Research Part A: General, 13(2), 91-109.

Nazari Adli, S., \& Donovan, S. (2018). Right to the city: Applying justice tests to public transport investments. Transport Policy, 66, 56-65. doi.org/10.1016/J.TRANPOL.2018.03.005

Pacione, M. (1982). The use of objective and subjective measures of life quality in human geography. Progress in Human Geography, 6(4), 495-514.

Peer, S., Knockaert, J., Koster, P., \& Verhoef, E. T. (2014). Over-reporting vs. overreacting: Commuters' perceptions of travel times. Transportation Research Part A: Policy and Practice, 69, 476-494. doi. org/10.1016/J.TRA.2014.07.005

Pereira, R. (2018). Ex-ante evaluation of the accessibility impacts of transport policy scenarios: Equity and sensitivity to travel time thresholds for bus rapid transit expansion in Rio de Janeiro. doi. org/10.17605/OSF.IO/SUT7R

Pereira, R., Schwanen, T., \& Banister, D. (2017). Distributive justice and equity in transportation. Transport Reviews, 37(2), 170-191.

Ross, W. (2000). Mobility and accessibility: The yin and yang of planning. World Transport Policy and Practice, 6(2), 13-19.

Social Exclusion Unit. (2003). Making the connections: Final report on transport and social exclusion (RPRT). London: Office of the Deputy Prime Minister.

van Acker, V., van Wee, B., \& Witlox, F. (2010). When transport geography meets social psychology: Toward a conceptual model of travel behavior. Transport Reviews, 30(2), 219-240.

van Exel, N. J. A., \& Rietveld, P. (2009). Could you also have made this trip by another mode? An investigation of perceived travel possibilities of car and train travelers on the main travel corridors to the city of Amsterdam, The Netherlands. Transportation Research Part A: Policy and Practice, 43(4), 374-385.

van Wee, B. (2016). Accessible accessibility research challenges. Journal of Transport Geography, 51, 9-16. doi.org/10.1016/j.jtrangeo.2015.10.018 
Vreeswijk, J., Thomas, T., van Berkum, E., \& van Arem, B. (2014). Perception bias in route choice. Transportation, 41(6), 1305-1321. doi.org/10.1007/s11116-014-9552-3

Wang, D., Brown, G., Liu, Y., \& Mateo-Babiano, I. (2015). A comparison of perceived and geographic access to predict urban park use. Cities, 42, 85-96. doi.org/10.1016/j.cities.2014.10.003

Witlox, F. (2007). Evaluating the reliability of reported distance data in urban travel behavior analysis. Journal of Transport Geography, 15(3), 172-183.

Ziegler, F., \& Schwanen, T. (2011). "I like to go out to be energized by different people": An exploratory analysis of mobility and wellbeing in later life. Aging \& Society, 31(5), 758. 